\title{
Simultaneous use of gastroscopy and laparoscopy for resection of gastrointestinal stromal tumors
}

\author{
Hüseyin Çiyiltepe, Ebubekir Gündeş, Durmuş Ali Çetin, Ulaş Aday, \\ Aziz Serkan Senger, Selçuk Gülmez, Mustafa Duman \\ Department of Gastroenterology Surgery, Kartal Koşuyolu High Specialization Training and Research Hospital, İstanbul, Turkey
}

\begin{abstract}
Introduction: Gastrointestinal stromal tumors (GIST) are rarely seen mesenchymal tumors originating from interstitial cells of Cajal. Today, with the wide use of minimally invasive techniques, laparoscopic surgery has come to the forefront in GIST surgery. The simultaneous use of laparoscopic gastric wedge resection (LGWR) and intraoperative gastroscopy is a surgical technique that relieves the surgeon. This article presents cases in which simultaneous intraoperative gastroscopic observations and LGWR were performed in appropriate GIST cases in one clinic.

Materials and Methods: The data of patients who underwent intraoperative gastroscopy and LGWR simultaneously due to GIST at the Kartal Koşuyolu High Specialty Training and Research Hospital between January 2014 and December 2015 were evaluated retrospectively.

Results: Between January 2014 and December 2015, 12 patients underwent intraoperative gastroscopy and LGWR simultaneously. When the endoscopic and radiological localizations of the tumors were examined, they were in the upper part in 7 patients, the middle part in 3 patients, and the lower part in 2 patients. The median tumor size was $4.4 \mathrm{~cm}$ (range: $2.7-6.3 \mathrm{~cm}$ ) and the size of the resected stomach material was 6.7 $\mathrm{cm}$ (range: 4.5-9 cm). According to the Fletcher risk classification, 7 patients were among the low risk group and 5 patients were considered to be in the moderate risk group.

Conclusion: The LGWR procedure for GIST is a reliable and feasible method for centers with advanced laparoscopic surgery experience. The advantages of simultaneous gastroscopy include determining tumor localization, verifying removal of the tumor with negative surgical margins before the development of stenosis, and providing simultaneous evaluation of bleeding or leakage from the stapler line.
\end{abstract}

Keywords: Endoscopy; gastrointestinal stromal tumor; laparoscopy.

\section{Introduction}

Gastrointestinal stromal tumors (GIST) are mesenchymal tumors originating from Cajal cells responsible for motor function in the intestinal wall. GISTs are a rarely seen tumor group and constitute less than $1 \%$ of the primary tu- mors of the gastrointestinal tract. Although the incidence in the community is unknown, the incidence is thought to be 1 in $100,000 .{ }^{[1,2]}$

GISTs can locate in any portion of the gastrointestinal tract from esophagus to rectum. ${ }^{[3]}$ In non-metastatic GISTs, the 
primary treatment option is surgery. The purpose of the surgery is to obtain a negative surgical margin. ${ }^{[4]}$

Today, with the common usage of minimally invasive techniques, laparoscopic surgery has come to the forefront in GIST surgery. ${ }^{[5]}$ However, there can be some difficulties during application of laparoscopic techniques. The small size of the tumor and the absence of extragastric prolapse or posterior gastric wall lesions make laparoscopic resection difficult. In addition, laparoscopic gastric wedge resection (LGWR) in tumors lying near the cardia or the pylorus is complicated by stenosis that may develop after resection. ${ }^{[6]}$

The simultaneous performance of LGWR with intraoperative gastroscopy renders the procedure easier thanks to gastroscopic and laparoscopic determination of the localization of the tumor. Other advantages of simultaneous intraoperative gastroscopy include prevention of stenosis that can develop after wedge resection especially in tumors near pylorus and cardia and provision of hemostasis by realizing intraoperative staple line bleedings. ${ }^{[7]}$

In this article, we aimed to present cases in which simultaneous intraoperative gastroscopic observations and LGWR were performed in appropriate GIST cases in our clinic.

\section{Materials and Methods}

Between January 2014 and December 2015, datas of the patients who underwent surgery due to GIST at Kartal Kosuyolu High Specialization Training and Research Hospital were evaluated retrospectively. All patients had standard preoperative evaluation along with gastroscopy and intravenous (iv) contrast enhanced thoraco-abdominal computed tomography (CT) for preoperative tumor localization. The files of the patients who underwent intraoperative gastroscopy and LGWR simultaneously were scanned. From the file datas the age, gender, height, weight, body mass index (BMI), endoscopic and radiological localization of tumor, the tumor size, type of operation, duration of operation, use of intraoperative gastroscopy, amount of hemorrhage during operation and from the pathology reports the tumor cell type, size, surgical margin distance, number of mitoses and GIST risk strafication scores were recorded.

Operations were performed under general anesthesia in lithotomy and reverse trendelenburg position. Veress needle was used to create pneumoperitoneum and a $10 \mathrm{~mm}$ port was inserted under umbilicus. With a $10 \mathrm{~mm}$ flexible laparoscope, ports of $5 \mathrm{~mm}, 10 \mathrm{~mm}$ and $5 \mathrm{~mm}$ were inserted under direct vision to the right midclavicular line, the left midclavicular line and the left axillary line respectively. Upper gastrointestinal endoscopy was performed by another surgeon at this stage for intraoperative tumor localization. In posterior gastric wall tumors omental dissection was performed first with the help of vessel sealing device (Ligasure ${ }^{\mathrm{TM}}$, Covidien, Mansfield, MA) and the posterior gastric wall was visualized. Under endoscopic observation, laparoscopic suture/clip marking was performed on the area where tumor was located. Subsequently, laparoscopic wedge resection was performed with the help of an endoscopic linear stapling device. During and after the resection, it was evaluated whether the tumor was within the safe surgical margin, whether it caused narrowing during resection of the tumor close to the cardia or pylorus, and whether there was bleeding or leakage from the stapler line, and the resection material was removed with endobag.

Written informed consent for the operation was obtained from all patients presented in this study. This study was conducted according to Declaration of Helsinki Ethical Principals for Medical Research.

Statistical analysis; Statistical Package for the Social Sciences (SPSS 21 Inc., Chicago, IL, USA) computer software was used for bio-statistical analyses. When the data were presented as mean values their standard deviation values, when they were presented as median values their minimum-maximum values were also stated.

\section{Results}

Between January 2014 and December 2015, a total of 21 patients underwent surgery for GIST in Kartal Kosuyolu High Specialization Training and Research Hospital. 9 of the
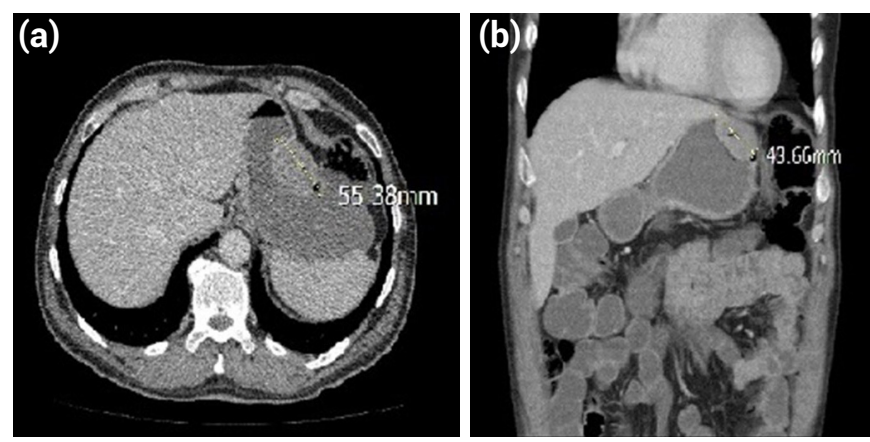

Figure 1. Computed tomography scan ([a] axial, [b] coronal) revealed a dumbbell shaped solid mass measuring approximately $5.5 \mathrm{~cm} \times 4 \mathrm{~cm}$. 


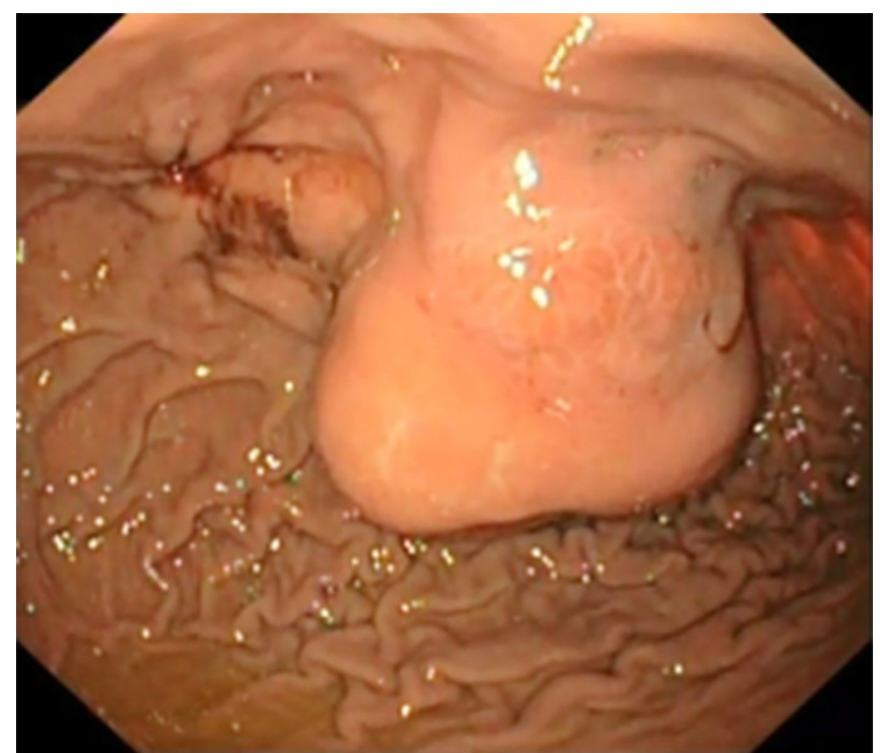

Figure 2. Intraoperative endoscopic view of GIST.

patients underwent open surgery (distal gastrectomy for 5 patients, wedge resection for 4 patients). In 12 patients, intraoperative gastroscopy and LGWR were performed simultaneously.

Among the patients who underwent intraoperative gastroscopy and LGWR simultaneously, 5 were male (41.6\%), 7 were female (58.3\%) and the mean age was 59.1 (46-75 years). The mean body mass index (BMI) of the patients was $31.7 \mathrm{~kg} / \mathrm{m}^{2}$ (min 27-max 37). In preoperative evaluation medical history was obtained from all patients. As standard, blood tests, upper gastrointestinal endoscopy

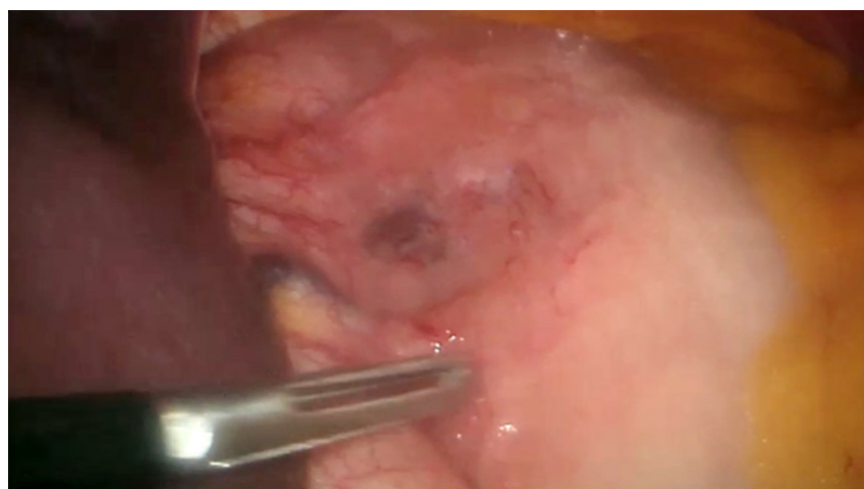

Figure 3. Intraoperative laparoscopic view of GIST.

and oral + i.v. contrast thoraco-abdominal CT were performed on all patients (Fig. 1). In preoperative evaluation endoscopic ultrasonography and fine needle aspiration biopsy were not performed on any of the patients.

In all of the patients, operation was completed laparoscopically using 4 ports as described previously (Fig. 2, 3). The $10 \mathrm{~mm}$ port area on the left midclavicular line was expanded and the materials were removed with an endobag. Median operative time was $128 \mathrm{~min}$ ( $\min 100-\max$ $150 \mathrm{~min}$ ) and mean operative blood loss was $28.5 \mathrm{ml}$. No bleeding or leakage from the staple line during simultaneous endoscopy was observed.

When the endoscopic and radiological locations of the tumors were examined, they were on anterior gastric wall in 8 patients and posterior gastric wall in 4 patients, in upper part of the stomach in 7 patients, middle part in 3

\section{Table 1. Pathological characteristics of GISTs}

\begin{tabular}{lccccccc} 
Cases & $\begin{array}{c}\text { Tumor } \\
\text { Location } \\
\text { Gastric } \\
\text { Wall }\end{array}$ & $\begin{array}{c}\text { Tumor } \\
\text { Localization }\end{array}$ & $\begin{array}{c}\text { Tumor } \\
\text { Size } \\
(\mathbf{c m})\end{array}$ & $\begin{array}{c}\text { Specimen } \\
\text { Size }(\mathbf{c m})\end{array}$ & $\begin{array}{c}\text { Surgical } \\
\text { Margin } \\
\text { Distance } \\
(\mathbf{m m})\end{array}$ & $\begin{array}{c}\text { Number of } \\
\text { Mitoses } \\
(/ 50 \text { HPF) }\end{array}$ & $\begin{array}{c}\text { GIST } \\
\text { risk group }\end{array}$ \\
\hline 1 & Posterior & Upper & $3 \times 3$ & $6 \times 5$ & 10 & 4 & Low \\
2 & Anterior & Upper & $5.5 \times 4$ & $7.2 \times 6$ & 14 & 2 & Intermediate \\
3 & Anterior & Upper & $6 \times 4.5$ & $9 \times 8$ & 16 & $2-3$ & Intermediate \\
4 & Anterior & Middle & $6 \times 4$ & $9 \times 8$ & 15 & $1-2$ & Intermediate \\
5 & Anterior & Upper & $4.5 \times 4.3$ & $6.5 \times 5.5$ & 25 & 4 & Low \\
6 & Anterior & Lower & $2.7 \times 2.5$ & $4.5 \times 3.5$ & 5 & 2 & Low \\
7 & Posterior & Middle & $3.5 \times 3$ & $6.8 \times 5.5$ & 15 & 3 & Low \\
8 & Anterior & Lower & $3.1 \times 2.1$ & $4.5 \times 3.5$ & 5 & 3 & Low \\
9 & Posterior & Upper & $4.2 \times 2.7$ & $6.1 \times 4$ & 12 & 2 & Low \\
10 & Anterior & Middle & $5.1 \times 3.8$ & $7.5 \times 5$ & 15 & 2 & Intermediate \\
11 & Posterior & Upper & $3.8 \times 2.3$ & $5.6 \times 4$ & 8 & $2-3$ & Low \\
12 & Anterior & Upper & $6.3 \times 4.1$ & $8 \times 5.6$ & 12 & 3 & Intermediate \\
\hline
\end{tabular}


patients and lower part in 2 patients far enough to pylorus or esophagogastric junction (Table 1).

The pathological features of the resected material are given in Table 1. The median tumor size was $4.4 \mathrm{~cm}$ (min $2.7 \mathrm{~cm}-\max 6.3 \mathrm{~cm}$ ) when the greatest size was considered, and the median resection material size of stomach was $6.7 \mathrm{~cm}(\min 4.5 \mathrm{~cm}-\max 9 \mathrm{~cm})$ again when the greatest size was considered. The result of the histopathologic evaluation was compatible with the postoperative GIST and negative surgical margins were succeeded in all resection material by pathological examination.

Risk classification was made as described by Fletcher et al. ${ }^{[8]}$ According to this, 7 patients were in low risk group and 5 patients were in middle risk group (Table 1).

\section{Discussion}

As there is no difusion to non-tumor tissue in GIST surgery, excision with negative surgical margin is sufficient instead of removal with $1-2 \mathrm{~cm}$ surgical margin as mentioned in the previous publications. Also, there is no need for lymph node dissection as the rates of nodal metastases are very low. ${ }^{[4]}$

The most appropriate approach for gastric submucosal tumors or GISTs is still controversial. While minimally invasive method is the preferred method for lesions $<2 \mathrm{~cm}$, the risk of malignancy increases with lesions larger than 5 $\mathrm{cm}$ and some authors put emphasis on the need to prefer open methods complying with the principles of oncology in this group of patients. ${ }^{[9]}$

Laparoscopic procedures are becoming increasingly widespread in GIST surgery. This technique was first used by Ohgami et al. in 1999 and 'lesion-lifting partial gastrectomy" technique was developed. ${ }^{[10]}$ The LGWR procedure for SMTs is a reliable and feasible method for centers with advanced laparoscopic surgery experience. ${ }^{[1]}$

LGWR is easily performed in small gastric SMTs with extraluminal extension located in the 1/3 middle part of the stomach, however, traditionally, open surgical methods are preferred to obtain a negative surgical margin in large tumors or in tumors located on posterior stomach wall or near the esophagogastric junction. ${ }^{[12]}$ Nevertheless, studies are available in the literature reporting successful performances of LGWR in large tumors, in tumors located in esophagogastric junction or on the posterior wall of the stomach. ${ }^{[13-15]}$
During LGWR, there is a risk of stenosis in tumors located in the esophagogastric junction or near the pylorus. With simultaneous gastroscopy, the intraluminal opening is easily evaluated and development of stenosis after inserting staple is also evaluated instantly. ${ }^{[16]}$ Other advantages of simultaneous gastroscopy include; giving information to the laparoscopist during operationin terms of best technique to perform, localization of the tumor, simultaneous verification of removal of the tumor with negative surgical margins, and simultaneous evaluation of staple line bleeds or leaks. ${ }^{[14,16]}$

Today, with the continuous development of endoscopic invasive techniques, simultaneous use of LGWR and endoscopic mucosal resection (EMR) has been increased. The authors of this technique reports that combination of conventional LGWR and EMR make operation easier and shorten the duration of the surgery. Especially in the tumors located in the entry or exit of the stomach, unnecessary stomach tissue is removed through conventional LGWR in relation to the angulation during staple insertion but, this can be avoided by combination of the operation with EMR. ${ }^{[1718]}$

The average tumor size in our series was $4.4 \mathrm{~cm}$. When the tumor location was taken into account, they were in upper part in 7 patients, in middle part in 3 patients and in lower part in 2 patient far enough to pylorus or esophagogastric junction. During surgery and in the follow-ups, no stenosis or bleeding due to resection was observed in any patient. When pathological pieces were examined in all patients, surgical margins were sufficient.

The limitations of the study are retrospective design, limited number of patients and lack of comparison group.

\section{Conclusion}

As a result; we think that intraoperative gastroscopy for all patients, who are plannig to go LGWR, will increase the surgical reliability as it gives information about intraoperative tumor localization and also enables evaluation of stenosis, hemorrhage and leaks that may develop at the same time. A comparative study of the patient group performed without gastroscopy during LGWR will reveal the advantages of concurrent endoscopy in a clearer way.

\section{Disclosures}

Financial Disclosure: The authors declared that this study has received no financial support.

Ethichs Committee Approval: Retrospective study. 
Peer-review: Externally peer-reviewed.

Conflict of Interest: None declared.

\section{References}

1. Hwang JH, Rulyak SD, Kimmey MB; American Gastroenterological Association Institute. American Gastroenterological Association Institute technical review on the management of gastric subepithelial masses. Gastroenterology 2006;130:2217-28. [CrossRef]

2. Shimizu S, Noshiro H, Nagai E, Uchiyama A, Mizumoto K, Tanaka M. Laparoscopic wedge resection of gastric submucosal tumors. Dig Surg 2002;19:169-73. [CrossRef]

3. Corless CL, Fletcher JA, Heinrich MC. Biology of gastrointestinal stromal tumors. J Clin Oncol 2004;22:3813-25.

4. DeMatteo RP, Lewis JJ, Leung D, Mudan SS, Woodruff JM, Brennan MF. Two hundred gastrointestinal stromal tumors: recurrence patterns and prognostic factors for survival. Ann Surg 2000;231:51-8. [CrossRef]

5. Kindblom LG, Remotti HE, Aldenborg F, Meis-Kindblom JM. Gastrointestinal pacemaker cell tumor (GIPACT): gastrointestinal stromal tumors show phenotypic characteristics of the interstitial cells of Cajal. Am J Pathol 1998;152:1259-69.

6. Bucher P, Villiger P, Egger JF, Buhler LH, Morel P. Management of gastrointestinal stromal tumors: from diagnosis to treatment. Swiss Med Wkly 2004;134:145-53.

7. Blay JY, Bonvalot S, Casali P, Choi H, Debiec-Richter M, Dei Tos AP, et al; GIST consensus meeting panelists. Consensus meeting for the management of gastrointestinal stromal tumors. Report of the GIST Consensus Conference of 20-21 March 2004, under the auspices of ESMO. Ann Oncol 2005;16:566-78. [CrossRef]

8. Fletcher CD, Berman JJ, Corless C, Gorstein F, Lasota J, Longley BJ, et al. Diagnosis of gastrointestinal stromal tumors: A consensus approach. Hum Pathol 2002;33:459-65. [CrossRef]

9. Otani Y, Furukawa T, Yoshida M, Saikawa Y, Wada N, Ueda M, et al. Operative indications for relatively small $(2-5 \mathrm{~cm})$ gastrointestinal stromal tumor of the stomach based on analysis of 60 operated cases. Surgery 2006;139:484-92. [CrossRef]

10. Ohgami M1, Otani Y, Kumai K, Kubota T, Kim YI, Kitajima M. Curative laparoscopic surgery for early gastric cancer: five years experience. World J Surg 1999;23:187-92. [CrossRef]

11. Choi SM, Kim MC, Jung GJ, Kim HH, Kwon HC, Choi SR, et al. Laparoscopic wedge resection for gastric GIST: long-term follow-up results. Eur J Surg Oncol 2006;33:444-7. [CrossRef]

12. Hiki N, Yamamoto $Y$, Fukunaga T, Yamaguchi T, Nunobe $S$, Tokunaga $M$, et al. Laparoscopic and endoscopic cooperative surgery for gastrointestinal stromal tumor dissection. Surg Endosc 2008;22:1729-35. [CrossRef]

13. Hyung WJ, Lim JS, Cheong JH, Kim J, Choi SH, Noh SH. Laparoscopic resection of a huge intraluminal gastric submucosal tumor located in the anterior wall: eversion method. $\mathrm{J}$ Surg Oncol 2005;89:95-8. [CrossRef]

14. Granger SR, Rollins MD, Mulvihill SJ, Glasgow RE. Lessons learned from laparoscopic treatment of gastric and gastroesophageal junction stromal cell tumors. Surg Endosc 2006;20:1299-304. [CrossRef]

15. Hepworth CC, Menzies D, Motson RW. Minimally invasive surgery for posterior gastric stromal tumors. Surg Endosc 2000;14:349-53. [CrossRef]

16. Mochizuki Y, Kodera Y, Fujiwara M, Ito S, Yamamura Y, Sawaki A, et al. Laparoscopic wedge resection for gastrointestinal stromal tumors of the stomach: initial experience. Surg Today 2006;36:341-7. [CrossRef]

17. Wilhelm D, von Delius S, Burian M, Schneider A, Frimberger E, Meining A, et al. Simultaneous use of laparoscopy and endoscopy for minimally invasive resection of gastric subepithelial masses - analysis of 93 interventions. World J Surg 2008;32:1021-8. [CrossRef]

18. Tsujimoto $H$, Yaguchi $Y$, Kumano I, Takahata R, Ono S, Hase K. Successful gastric submucosal tumor resection using laparoscopic and endoscopic cooperative surgery. World J Surg 2012;36:327-30. [CrossRef] 